Received Date : 10-Jul-2016

Revised Date : 13-Jan-2017

Accepted Date : 17-Feb-2017

Article type : Research Article

Short title/Authors running head: A self-management group for young people and families with Type 1 diabetes $\bullet R$. A. Cai et al.

\title{
Development of an acceptable and feasible self- management group for children, young people and families living with Type 1 diabetes
}

\author{
R. A. Cai ${ }^{1}$, R. I. G. Holt ${ }^{2}$, L. Casdagli ${ }^{1}$, R. M. Viner ${ }^{3}$, R. Thompson ${ }^{4}$, K. \\ Barnard $^{5}$ and D. Christie ${ }^{1}$
}

${ }^{1}$ UCLH NHS Foundation Trust Child and Adolescent Psychological Services, London, ${ }^{2}$ Human Development and Health Academic Unit, University of Southampton, Southampton, ${ }^{3}$ UCL Institute of Child Health and ${ }^{4}$ UCLH NHS Foundation Trust Paediatric and Adolescent Diabetes Service, London and ${ }^{5}$ Faculty of Health and Social Science, Bournemouth University, Bournemouth, UK

Correspondence to: Deborah Christie. E-mail: Deborah.christie@uclh.nhs.uk

What's new?

- This study developed an intervention to help children with Type 1 diabetes and their parents improve recognition of hypoglycaemia and hyperglycaemia, and reflect on experiences and choices about when and how to put diabetes knowledge into practice.

- The intervention encourages parents and young people to see themselves as experts in their diabetes and allows young people to demonstrate diabetes knowledge.

- It is important to offer parents and young people the chance to learn diabetes-related information from each other.

This article has been accepted for publication and undergone full peer review but has not been through the copyediting, typesetting, pagination and proofreading process, which may lead to differences between this version and the Version of Record. Please cite this article as doi: 10.1111/dme.13341

This article is protected by copyright. All rights reserved. 


\section{Abstract}

Aims This study developed an acceptable and feasible self-management intervention that addresses the self-identified needs of children and young people with Type 1 diabetes and their parents.

Methods Phase 1 reviewed previous interventions and interviewed the clinical team, young people and families. Phase 2 ran three age-matched focus groups with 11 families of children aged 8 16 years. Feedback was used to modify the workshop. Phase 3 evaluated feasibility of delivery, as well as the effects on metabolic control, quality of life and fear of hypoglycaemia, measured at baseline and 1-3 months post intervention.

Results Eighty-nine families were invited to take part. Twenty-two (25\%) participated in seven pilot groups (median age of young people 10 years, $36 \%$ girls). The intervention comprised a developmentally appropriate workshop for young people and parents addressing: (1) blood glucose control, (2) the potential impact of long-term high $\mathrm{HbA}_{1 c}$, (3) the effects of 'hypos' and 'hypers', (4) self-management techniques and (5) talking confidently to people about diabetes. Participants were enthusiastic and positive about the workshop and would recommend it to others. Young people liked sharing ideas and meeting others with diabetes, while parents enjoyed listening to their children talk about their diabetes knowledge.

Conclusions Families living with Type 1 diabetes participated in developing a self-management group intervention. Although we demonstrated acceptability and feasibility, the pilot study results do not support the development of a randomized control trial to evaluate the effectiveness in improving $\mathrm{HbA}_{1 \mathrm{c}}$.

\section{Introduction}

Hypoglycaemia is the commonest adverse event associated with insulin treatment in both Type 2 and Type 1 diabetes [1]. Hypoglycaemic episodes are not only physically aversive and dangerous, but cause social embarrassment for children and adolescents. As a result, fear of hypoglycaemia in both parents and young people can potentially lead to two problems [2]. The first is reduced quality of life, underpinned by anxiety about the unpleasantness of 'hypos', the relentless nature of daily management and a lack of confidence that others are able or willing to provide appropriate care [3]. The second is 'hypoglycaemia avoidance behaviour' [1], aimed at preventing low blood glucose. These can often be maladaptive, such as eating large snacks or allowing hyperglycaemia as a precaution.

The subsequent rise in $\mathrm{HbA}_{1 \mathrm{c}}$ as a consequence of these short-term coping responses worsens the risks of long-term complications [1]. Interventions to support children with Type 1 diabetes and reduce fear of hypoglycaemia are needed [3]. There is an extensive literature on programmes designed to address general regimen adherence in children and adolescents with Type 1 diabetes [4,5], but little has been published on interventions specifically for the parents of children with Type 1 diabetes. Recently evaluated structured educational programmes have focused on increasing knowledge and skills, and offering practical ways to reduce $\mathrm{HbA}_{1 \mathrm{c}}$ and hyperglycaemia; however, behaviour change strategies that focus on fear of hypoglycaemia are not specifically addressed [6,7]. Moreover, in a previous systematic review [8], no interventions were found that focus specifically on reducing parental fear of hypoglycaemia which might mediate or moderate the ability of parents to put education and knowledge into practice.

This article is protected by copyright. All rights reserved. 
We therefore undertook a project aimed at: (1) developing an age-appropriate programme that addresses the self-identified needs of children and young people with Type 1 diabetes and their parents in relation to hypoglycaemia and blood glucose management; and (2) assessing the acceptability (usefulness and enjoyableness for young people and their families) and feasibility of delivering the programme as a pilot undertaken within a clinical service.

\section{Methods}

We undertook our study in three phases, the first two developed and refined the intervention, and the third evaluated a pilot of the intervention. Ethics approval was received from NRES Committee London-Hampstead.

\section{Development}

\section{Phase 1}

The research team identified key themes from their clinical practice and integrated them with themes identified in the literature and a recently evaluated structured education programme [9]. The suggested intervention was a four-session family programme run once a month that would focus on managing hypoglycaemia.

Five children and young people attending the Child and Adolescent UCLH Diabetes clinics (median age 10 years, range 9-16 years; median duration of diabetes 4 years, range 2-13 years) and their parents were approached. Feedback from these interviews indicated that families wanted a single group run over a day and that the content should not be too new or complicated. Young people and parents were clear that they did not want to attend a workshop that focused on fear of hypoglycaemia, but wanted to use the time to address annoyance with and the practicalities of diabetes selfmanagement.

\section{Phase 2}

The intervention content and structure were redesigned using these ideas to be run over a single day, and focused on overall blood glucose management and the effects of diabetes on daily life. Ideas from the blood glucose awareness training programme were used to inform the workshop content, which included family group sessions on: (1) how insulin and food affect blood glucose, (2) the potential impact of long-term high $\mathrm{HbA}_{1 c}$, (3) the effects of hypoglycaemia and hyperglycaemia on daily living, (4) self-management techniques and (5) talking to people about diabetes with confidence. Children, young people and families (including those who had been interviewed previously) were then invited to review the draft intervention. Three focus groups were run with different age groups: one for four adolescents (14-16 years) and four mothers; one for three children (10-11 years), two mothers, one father and one brother; and one for four children (8-10 years), four mothers and one sister. Transcriptions were made from audio recordings of the three groups. Feedback was discussed by the clinical intervention team (DC, LC and RC) and further amendments were made.

\section{Delivery of the pilot study (Phase 3)}

Families with children and young people aged between 8 and 16 years with Type 1 diabetes were contacted by phone or approached in clinic. Families who agreed to participate were offered a group based on the young person's age and gender. Reasons for non-participation were recorded to learn

This article is protected by copyright. All rights reserved. 
about barriers to participation and ensure equitable access. We used a mixed models approach to evaluate the feasibility of delivery, recruitment rates, interest in participation and effectiveness of the intervention and generate data to inform a full randomized controlled trial.

\section{The intervention}

The pilot intervention workshops were delivered by two clinical psychologists, a diabetes clinical nurse specialist and an assistant psychologist. Table 1 shows a summary of the different activities that were included.

Most of the day, young people and parents worked together. In the session after lunch, the young people and parents were in separate groups, each facilitated by a qualified clinical psychologist. The underlying philosophy of the intervention approach came from systemic theories that assume families are aware of what they 'need' to do; however, they are not willing, able or ready to put this knowledge into practice. 'Scaffolding' questions help 'draw information out' [10]. Learning is a collaborative effort between family and provider, reducing the sense of an expert imposing knowledge, moving towards a shared venture. This active rather than passive approach is effective at eliciting behaviour change in other areas [11]. We also incorporated evidence-based techniques designed to engage young people in wanting to change their behaviour $[12,13]$.

\section{Participants}

Eligible participants were between 8 and 16 years old, at least 6 months post diagnosis, with no additional comorbid conditions and sufficient spoken English to participate in the groups. The Paediatric and Adolescent Diabetes Service at University College London Hospital (UCLH) has 400 children with Type 1 diabetes, of whom $~ 300$ were eligible to participate in the pilot. Twenty-five participants were required to achieve pilot and feasibility objectives. Estimating a dropout rate of $20 \%$, we aimed to recruit 32 participants.

\section{Outcome measures}

Primary outcomes were acceptability and feasibility of delivery of the intervention. Acceptability was assessed using qualitative and quantitative evaluation scores. After each workshop was completed, young people and parents were asked to indicate on a scale, from 1 to 10 , how likely they would be to recommend the programme to other young people and families living with diabetes. Feasibility was measured by collecting data on the uptake of the programme, final attendance and drop-out rate, as well as potential barriers to participation.

In addition to the feasibility and acceptability data, participants' mean $\mathrm{HbA}_{1 \mathrm{c}}$ over a period of 12 months (median 12 months; range 6-12) before the pilot study was used as baseline $\mathrm{HbA}_{1 \mathrm{c}}$. The first available $\mathrm{HbA}_{1 \mathrm{c}}$ provided 2-6 months after the intervention group was completed was used as the follow-up $\mathrm{HbA}_{1 \mathrm{c}}$.

This article is protected by copyright. All rights reserved. 
One month after the workshop, families were contacted and invited to complete follow-up questionnaires. They were asked how useful they had found the day, how much they enjoyed the activities and how comfortable they were speaking about diabetes since participation. They were also asked if they had changed anything in their diabetes management and what benefits they perceived from participating in the programme. Lastly, families were given the opportunity to provide feedback for the intervention content, design and delivery. All interviews were transcribed and analysed using qualitative content analysis [14]. All feedback and evaluations were carefully reviewed in order to develop a comprehensive coding system, and codes with similar content were grouped into mutually exclusive themes. Two of the authors (RAC and DC) read and analysed the transcripts separately, and then compared the results. The codes and themes were developed and refined by discussions among the authors until consensus was reached.

\section{Number of hypoglycaemic events}

Parents were asked how many times their child had experienced an episode of hypoglycaemia in the past month.

\section{Hypoglycaemia Fear Survey}

The Hypoglycaemia Fear Survey (HFS)-II was developed to measure behaviours (10-item behaviour subscale) and anxiety (15-item worry subscale) related to hypoglycaemia in diabetes $[15,16]$. The HFS behaviour subscale records inappropriate behaviour related to fear (maintenance of high blood glucose), as well as appropriate behaviours involving avoidance of hypoglycaemic risks by other behaviours. Each item is rated on a five-point Likert scale ranging from 1 (never) to 5 (always). HFS

subscale scores are obtained by summing the items for the behaviour and worry subscales separately, and the HFS total score is obtained by summing both subscale scores. Fear of hypoglycaemia is classified as high if participants scored 'often' or 'all the time' on at least one of the items in the worry scale [17].

\section{Additional questionnaires}

Three questionnaires were given to families and young people before and after the groups to see if they would be acceptable and could be easily completed. The three measures used were: the diabetes module from the Paediatric Quality of Life Inventory (PedsQL 3.0), The Diabetes Family Responsibility Questionnaire [18] and the Self-Care Inventory [19].

This article is protected by copyright. All rights reserved. 


\section{Results}

\section{Feasibility}

\section{Recruitment}

Between 28 July 2014 and 9 December 2014, 89 eligible families (44\% females; mean age 12.4 years, range 8-16) received study information, either prior to attending or during their clinic appointment. They were then approached to take part during clinic or were called on the telephone. Both mothers and fathers were invited to participate in sessions along with their children.

\section{Uptake, attendance, and drop-out rate}

Thirty-four (33\%) of the 89 families contacted consented to participate (41\% female; mean age 11.8 years, range $8-16$ years), and were contacted to arrange a convenient date to attend a group. The groups were based on the young person's age (separated into 8-10,11-12 and 13-16 year olds). Four (or five) families were assigned to each group. Single and mixed gender groups were available. Some families requested groups run in the school holidays. This was arranged where possible. All participants were contacted the week before the group to remind them of the arrangements. The median number of times families were contacted to recruit them into the study was 4 (range 1-8). Families took between 0 and 63 days before agreeing to take part in the study.

One participant withdrew from the study after giving consent, with an additional 11 cancelling the week before or on the morning of the group. The final 22 families participated in seven groups (2-4 families per group) delivered by two qualified clinical psychologists, an assistant psychologist and a diabetes clinical nurse specialist. One group arranged in the half-term holiday was cancelled due to insufficient participants for that session.

\section{Barriers to participation}

The main reason given for declining to take part was being unwilling to miss school $(N=35)$. Other reasons included being busy and not having time $(N=10)$, general disinterest in the study $(N=7)$, and living too far away $(N=2)$ or transportation issues $(N=1)$.

\section{Baseline data collection}

A median of 3 (range 1-15) attempts were made to contact people to collect baseline data. Baseline data were collected a median of 19.5 days (range 1-115 days) before the group began.

\section{Follow-up data}

Follow up data were collected in clinic (three young people, six parents), over the phone (14 young people, 9 parents) or via post/email (one young person, four parents). A median of 5.5 (range 1-20) attempts were made to contact people to complete the follow up data. It took a median of 45 days (range 22-109) to collect follow-up data. One family was unwilling to complete the follow up questionnaires and three families could not be contacted. Table 2 describes the baseline demographics for people approached, consented and finally participated.

\section{Acceptability}

Quantitative ratings indicated that parents and young people found the day useful and enjoyable, and would recommend it to other families (Table 3). Six themes emerged from the content analysis, which are illustrated by quotes from participants. Quotes from young people are identified by gender and age.

This article is protected by copyright. All rights reserved. 
General enjoyment of the day

Participants were unanimously enthusiastic and positive about the workshop:

I enjoyed the day because we got to explain how we feel and share what we are going through. (Girl, 9)

The day has boosted my child's confidence. She was very apprehensive about attending but was made to feel relaxed and valued during the day. She was able to talk in front of new people and share her knowledge which was a huge achievement for her. (Parent) My son used to have a negative attitude towards hospitals, but this was much more fun and engaging. (Parent)

\section{Parents listening to their children}

Parents enjoyed listening to their children talk about their diabetes knowledge:

It was good to see that she can manage it, and understands what affects her blood sugar and see her confidence grow from sharing her knowledge with others and feeling comfortable with talking to others. (Parent)

It was nice that he realized he is very knowledgeable. It also made me see how wonderful and amazing he is. (Parent)

I will allow her more freedom and not be the one making all the decisions, because she clearly knows what is going on and what she needs to do when she's high or low. (Parent)

\section{Comfort with sharing and speaking about diabetes}

Both young people and parents liked sharing ideas and meeting others with diabetes. Young people also indicated that they felt more comfortable speaking about diabetes after participation as opposed to before:

It was amazing to realize that others felt the way I did. (Girl, 11)

It was interesting to see how other people are affected differently by low or high blood sugar. (Boy, 13)

It's good to know that others are going through with the same situation, it makes you feel connected. Otherwise you think you're the only one. You don't get many opportunities like this. (Parent)

\section{Recognizing personal strengths}

Parents and young people identified how working in the group had helped them see they were doing well:

I know more about diabetes than I think and know how to look after myself. (Boy, 15)

I realized that we're all coping quite well, even when we think we're not, and our worries are all quite similar. (Parent)

I realized that I deal quite well with pressure and we're not falling apart - I can pat myself on the back for that. (Parent)

This article is protected by copyright. All rights reserved. 


\section{Learning about diabetes}

Even though many participants had extensive education on diabetes, they still found that the day enabled them to learn more about diabetes:

I learned what $\mathrm{HbA}_{1 \mathrm{c}}$ means and stands for. (Girl, 9)

The insulin game showed me what things affected blood glucose, and how one thing can make it go either way. (Boy, 13)

I've learned more about diabetes today than I did in three years! (Parent)

\section{Improving self-management}

I will be more aware of what happens when I'm high or low, and pay more attention to what my body is telling me. (Boy, 14)

My son managed to do a cannula change with confidence - this has proved challenging in the past so it is a huge step forward. (Parent)

In the young people's session, a leaflet was developed called 'What you need to know about T1 Diabetes'. This is available on the UCLH diabetes website [20].

\section{Quantitative results}

Mean $\mathrm{HbA}_{1 \mathrm{c}}$ was $66 \pm 12 \mathrm{mmol} / \mathrm{mol}(8.2 \pm 1.1 \%)$ before and $65 \pm 13 \mathrm{mmol} / \mathrm{mol}(8.1 \pm 1.2 \%)$ after the intervention. The median number of hypoglycaemic episodes in the month preceding completion of baseline assessment was 9.0 [interquartile range (IQR) 2.3-9.0], and in the month preceding collection of follow-up data (which was at least a month after the group) was 4.0 (IQR 2.0-9.0). Table 4 shows the number of children, young people and parents identified as having high fear of hypoglycaemia. It also shows the HFS 'behaviour' and 'worry' scores at baseline and follow up for young people and parents who had high fear of hypoglycaemia at baseline. As a feasibility study, it was not powered to detect pre-post differences, therefore no statistical tests have been completed. Because the study was primarily designed to assess the general acceptability and feasibility of the intervention, the data from all questionnaires are not given.

\section{Discussion}

By working with young people and their families, we developed an acceptable programme that is ageappropriate and addresses the self-identified needs of children and young people with Type 1 diabetes and their parents in relation to managing hypoglycaemia and hyperglycaemia. All the focus group participants were clear that it was essential to include several aspects of glucose management. This showed that it was not practical or feasible to offer families an intervention focusing only on fear of hypoglycaemia. Young people and parents also helped identify topics of interest that can potentially

This article is protected by copyright. All rights reserved. 
improve blood glucose control. The content was delivered using psychological approaches that were designed to increase young people's confidence in self-management and parental confidence in their children's ability to self-manage. In addition, young people and families preferred for the intervention to be delivered as a one-day programme.

Families were happy to complete the questionnaires that were used in the study; however, the small sample size meant that statistical comparison of the baseline and follow-up data is not possible. It was possible to deliver the groups, although recruitment was a challenge and would not have been feasible in a normal clinical context. Although not tested statistically, parents appear to have higher fear of hypoglycaemia than children, with no apparent change following the intervention. Although formal statistical analysis was not undertaken because of the sample size, there was a small reduction in the number of 'hypos' reported by the families without apparently compromising $\mathrm{HbA}_{1 \mathrm{c}}$ levels. Fewer 'hypos' may mediate the relationship between better blood glucose management and lower fear of hypoglycaemia in the long term $[21,22]$.

Families also reported several positive changes in relation to the day, such as being able to listen to and understand each other more, feeling more comfortable speaking about diabetes, learning more about diabetes, recognizing personal strengths and improving self-management. For example, young people appreciated being listened to and felt their knowledge was valued and respected, and commented on how the activities helped them pay more attention to their bodies and how to recognize symptoms of hypo- or hyperglycaemia.

In clinics, families repeatedly request additional support, yet we had to call up to eight times to discuss the project with some families and the time that it took to decide to take part ranged between 0 and 63 days (median 8.5 days). The amount of time this would take a member of the clinical team to complete would impact significantly on the ability of most services offering the programme. Despite $>90 \%$ of parents scoring high fear of hypoglycaemia on the HFS scales, only $33 \%$ initially agreed to participate with an additional third of these families dropping out at the last minute bringing the final recruitment rate to $25 \%$. Last minute cancellation and drop-out has an impact on clinical delivery because it is much harder to run a group if only one or two participants turn up on the day [23]. This is a common paradox for clinical teams who are asked for support by families; finding the right kind of support clearly needs to be individualized.

Families with children in year 7 or above were unwilling to miss school to attend the groups. Groups were offered in the holidays for young people in year $9 / 10$; however, these had to be cancelled due to other commitments, suggesting that the intervention did not appeal to older age groups. Future groups could test out weekend sessions to better accommodate young people's and parent's schedules.

This article is protected by copyright. All rights reserved. 
We found practical difficulties collecting data, with significant variation in the time between recruitment and collection of baseline data and when groups began. There were also practical difficulties collecting follow-up data a month after the group finished as planned. This would need to be thought about carefully in collection of outcomes for a clinical service. Collection of timely outcome data for the study was only possible with a dedicated research assistant and still only achieved $80 \%$ follow up.

The study showed that it was possible to design an intervention that was evaluated positively by $25 \%$ of eligible families and that all the families, children and young people found the groups enjoyable and would recommend them to other families. Qualitative feedback suggests that the group had an impact on how parents perceived their children's ability to manage their diabetes and on young people's ability to communicate with others about diabetes. The programme offered families the chance to learn diabetes-related information from each other, and to reflect on and acknowledge each other's strengths, experiences and abilities, which is a very different approach from current standard education programmes. This had an impact on parent-child relationships and communication, as well as on how they feel about diabetes and how to manage it in the future, which was reflected in the potential reduction in hypoglycaemic episodes without compromising overall metabolic control. However, current acceptability and perceived benefits of the programme are limited to a small sample of participants.

In summary, we developed an intervention to help children, young people and their parents/carers manage blood glucose levels and general issues of living with Type 1 diabetes. Involving children and families in the development process helped to ensure the acceptability of the final programme for those that chose to participate. The study identified significant feasibility issues regarding recruitment and organization of the groups due to participant withdrawals. There were also practical difficulties with collecting baseline and follow-up data, such as the number of attempts needed to contact families and the expected drop-out rate.

\section{Funding sources}

This project was funded by a grant from the Diabetes Research Wellness Foundation

\section{Competing interests}

None declared.

\section{Acknowledgements}

We would like to thank the young people and families that took part in the development of the intervention and participated in the focus groups. We would also like to thank Dr Hannah Duncan, Madeline Harris, Louise Potts, Emily Storr and Laura Rose for helping to run the groups.

This article is protected by copyright. All rights reserved. 


\section{References}

1 Wild D, von Maltzahn R, Brohan E, Christensen T, Clauson P, Gonder-Frederick L. A critical review of the literature on fear of hypoglycemia in diabetes: implications for diabetes management and patient education. Patient Educ Couns 2007; 68: 10-15.

2 Brouhard BH. Hypoglycemia. In: Travis LB, Brouchard BH, Schreiner BJ, editors. Diabetes Mellitus in Children and Adolescents. Philadelphia: W.B. Saunders, 1987; pp. 169-178.

3 Barnard K, Thomas S, Royle P, Noyes K, Waugh N. Fear of hypoglycaemia in parents of young children with type 1 diabetes: a systematic review. BMC Pediatr 2010; 10: 50.

Delamater AM. Psychological care of children and adolescents with diabetes. Pediatr Diabetes 2009; 10: 175-184

Hampson SE, Skinner TC, Hart J, Storey L, Gage H, Foxcroft D et al. Effects of educational and psychosocial interventions for adolescents with diabetes mellitus: a systematic review. Health Technol Assess 2001; 5: 1-79.

6 Christie D, Strange V, Allen E, Oliver S, Wong I, Smith F et al. Maximising engagement, motivation and long term change in a Structured Intensive Education Programme in Diabetes for children, young people and their families: Child and Adolescent Structured Competencies Approach to Diabetes Education (CASCADE). BMC Pediatr 2009; 9: 57.

7 Gregory J, Robling M, Bennert K, Channon S, Cohen D, Crowne E et al. Development and evaluation by a cluster randomised trial of a psychosocial intervention in children and teenagers experiencing diabetes: the DEPICTED study. Health Technol Assess 2011; 15: 1202.

8 Patton SR, Dolan LM, Henry R, Powers SW. Fear of hypoglycemia in parents of young children with type 1 diabetes mellitus. J Clin Psychol Med Settings 2008; 15: 252-259.

9 Sawtell M, Jamieson L, Wiggins M, Smith F, Ingold A, Hargreaves K et al. Implementing a structured education program for children with diabetes: lessons learnt from an integrated process evaluation. BMJ Open Diabetes Res Care 2015; 3: e000065.

10 Vygotsky LS. Mind in Society: The development of higher psychological processes. Cambridge, MA: Harvard University Press, 1978.

11 Albarracín D, Gillette JC, Earl AN, Glasman LR, Durantini MR, Ho M-H. A test of major assumptions about behavior change: a comprehensive look at the effects of passive and active HIV-prevention interventions since the beginning of the epidemic. Psychol Bull 2005; 131: 856-897.

12 Christie D, Channon $\mathrm{S}$. The potential for motivational interviewing to improve outcomes in the management of diabetes and obesity in paediatric and adult populations: a clinical review. Diabetes Obes Metab 2014; 16: 381-387.

13 George E, Iveson C, Ratner H. Problem to Solution: Brief therapy with individuals and

This article is protected by copyright. All rights reserved. 
families. London: BT Press, 1999.

14 Graneheim UH, Lundman B. Qualitative content analysis in nursing research: concepts, procedures and measures to achieve trustworthiness. Nurse Educ Today 2004; 24: 105-112.

15 Gonder-Frederick L, Nyer M, Shepard JA, Vajda K, Clarke W. Assessing fear of hypoglycemia in children with Type 1 diabetes and their parents. Diabetes Manag (Lond) 2011; 1: 627-639.

16 Gonder-Frederick LA, Vajda KA, Schmidt KM, Cox DJ, Devries JH, Erol O et al. Examining the behaviour subscale of the Hypoglycaemia Fear Survey: an international study. Diabet Med 2013; 30: 603-609.

17 Hajós TRS, Polonsky WH, Pouwer F, Gonder-Frederick L, Snoek FJ. Toward defining a cutoff score for elevated fear of hypoglycemia on the hypoglycemia fear survey worry subscale in patients with type 2 diabetes. Diabetes Care 2014; 37: 102-108.

18 Anderson BJ, Auslander WF, Jung KC, Miller JP, Santiago JV. Assessing family sharing of diabetes responsibilities. J Pediatr Psychol 1990; 15: 477-492.

19 La Greca AM. Brief Manual of the Self Care Inventory. University of Miami, FL, 1992.

20 University College London Hospitals. What You Need to Know About Type 1 Diabetes. Available at https://www.uclh.nhs.uk/OurServices/ServiceA-

Z/CYPS/PDIAB/Documents/What young people would like everyone to know about Type 1 Diabetes.pdf Last accessed 1 June 2016.

21 Gonder-Frederick LA, Fisher CD, Ritterband LM, Cox DJ, Hou L, DasGupta AA et al. Predictors of fear of hypoglycemia in adolescents with type 1 diabetes and their parents. Pediatr Diabetes 2006; 7: 215-222.

22 Leiter LA, Yale JF, Chiasson JL, Harris S, Kleinstiver P, Sauriol L. Assessment of the impact of fear of hypoglycemic episodes on glycemic and hypoglycemia management. Can $J$ Diabetes 2005; 29: 186-192.

23 Christie D, Thompson R, Sawtell M, Allen E, Cairns J, Smith F et al. Structured, intensive education maximising engagement, motivation and long-term change for children and young people with diabetes: a cluster randomised controlled trial with integral process and economic evaluation - The CASCADE study. Health Technol Assess (Rockv) 2014; 18: 1-202.

This article is protected by copyright. All rights reserved. 
Table 1 A summary of the different activities included in the workshop

\begin{tabular}{|c|c|c|}
\hline $\begin{array}{l}\text { Time } \\
(\operatorname{mins})\end{array}$ & Activity & \\
\hline 15 & 'Like' boards & $\begin{array}{l}\text { Ice breaker with flip charts for parents and children in two groups facilitated by staff } \\
\text { discussing favourite foods, music, hobbies and activities }\end{array}$ \\
\hline 10 & Introductions & $\begin{array}{l}\text { In a large group, each person says one true thing and one untrue thing about } \\
\text { themselves and children have to guess which is the true thing }\end{array}$ \\
\hline 15 & $\begin{array}{l}\text { Questions you } \\
\text { want answered }\end{array}$ & $\begin{array}{l}\text { Parents, children and young people in separate groups with a facilitator thinking } \\
\text { about if the day went well, what questions they would want answered. Questions are } \\
\text { read out and placed on a flip chart }\end{array}$ \\
\hline 25 & $\begin{array}{l}\text { Blood glucose } \\
\text { and insulin }\end{array}$ & $\begin{array}{l}\text { A game to show how insulin works as a key to allow glucose to enter cells and what } \\
\text { happens if insulin not present. Young people play the role of the cell, the door, the } \\
\text { insulin and blood glucose. Worksheet given out to take home }\end{array}$ \\
\hline
\end{tabular}

Break

Factors influencing blood glucose levels

$\mathrm{HbA}_{1 \mathrm{c}}-\mathrm{DCCT}$ trial

Hypoglycaemia and hyperglycaemia

Parents' reflections

Lunch

Bring back for feedback
Parents and children in different groups with a facilitator. Each group given a number of cards describing different factors that affect blood glucose levels and have to decide if they make blood glucose go up, down or both. Facilitator goes through the different cards encouraging young people to give reasons for their choices.

Worksheet with correct answers given out to take home

Workshop leader talks through what $\mathrm{HbA}_{1 \mathrm{c}}$ stands for (using developmentally appropriate language) and shows the DCCT complications chart to illustrate why $\mathrm{HbA}_{1 \mathrm{c}}$ is given such importance by parents and clinic staff

Parents/8-12- Young people meet on their own with two workshop leaders. The specific activity is year age group designed by the psychologist during the lunch break and depends on the developmental and cognitive level of the group. The aim is to invite children to identify their strengths, abilities and resources, and think about ways to answer questions other people have about diabetes. A variety of media are used during this session

Parents are offered a group session facilitated by a workshop leader (a qualified psychologist). Parents are invited to use the session to discuss whatever topic they would like, so each session is always different. They are also reminded of the questions they raised at the beginning of the day to see if any of these have been answered

Parents return to hear about the output the young people have designed 
30

$30-40$
Question time

Blueprint for success - going to do differently

Based on the BBC programme format, young people make up a panel and answer the questions that were identified at the beginning of the day. Parents act as the audience

Young people are interviewed about what they enjoyed, what they learned, what they will do differently as a result of attending the workshop and what they have appreciated about each other. The answers are written on certificates called a 'blueprint for success'

Parents are then invited to reflect on what they heard their children talk about, and are asked what they were struck by and what they will do differently. They are also asked to contribute their appreciations of the young people

5 Evaluation Post- Participants are invited to say, on a scale of 1 to 10, whether they would recommend it® notes the day to other families with diabetes

Table 2 Demographic characteristics data and $\mathrm{HbA}_{1 \mathrm{c}}$ for the 89 approached, the $33 / 34$ that consented and completed the baseline questionnaire, and the 22 that participated.

\begin{tabular}{|c|c|c|c|}
\hline & $\begin{array}{l}\text { Approached } \\
(N=89)\end{array}$ & $\begin{array}{c}\text { Completed } \\
\text { baseline } \\
\text { questionnaire } \\
(N==33)\end{array}$ & $\begin{array}{l}\text { Actual participants } \\
\qquad(N=22)\end{array}$ \\
\hline Female, $N(\%)$ & $39(44 \%)$ & $19(48 \%)$ & $8(36 \%)$ \\
\hline Age (years), mean (SDSD) & $12.4(2.5)$ & $11.8(2.7)$ & $11.2(2.8)$ \\
\hline \multicolumn{4}{|l|}{ Ethnicity, $N(\%)$} \\
\hline White, $N(\%)$ & $72(81 \%)$ & $33(83 \%)$ & $17(77 \%)$ \\
\hline Asian/Asian British, $N(\%)$ & $8(9 \%)$ & $4(10 \%)$ & $3(14 \%)$ \\
\hline Black, $N(\%)$ & $6(7 \%)$ & $2(5 \%)$ & $1(5 \%)$ \\
\hline Other Ethnicity, $N(\%)$ & $3(3 \%)$ & $1(3 \%)$ & $1(5 \%)$ \\
\hline $\begin{array}{l}\text { Time since diagnosis (years), } \\
\text { mean (SDSD) }\end{array}$ & $6.3(3.4)$ & $6.1(3.4)$ & $6.2(3.2)$ \\
\hline $\begin{array}{l}\text { Time since enrolled at clinic (years), mean } \\
\text { (SDSD) }\end{array}$ & $3.6(2.8)$ & $3.6(2.6)$ & $3.91(3.0)$ \\
\hline \multicolumn{4}{|l|}{$\mathrm{HbA}_{1 \mathrm{c}}$, mean $(\mathrm{SD}) *$} \\
\hline $\mathrm{HbA}_{1 \mathrm{c}}(\mathrm{mmol} / \mathrm{mol})$, mean $(\mathrm{SD}) * \mathrm{mmol} / \mathrm{mol}$ & $69(11)$ & $64(8)$ & $66(12)$ \\
\hline $\mathrm{HbA}_{1 \mathrm{c}}(\%)$, mean $(\mathrm{SD}) * \%$ & $8.5(1.4)$ & $8.0(1.0)$ & $8.2(1.1)$ \\
\hline $\begin{array}{l}\text { Number of hypoglycaemic episodes in the } \\
\text { last month, } \\
\text { Mmedian (IQR) }\end{array}$ & Not availableA & $9.0(7.0)$ & $9.0(6.8)$ \\
\hline
\end{tabular}

This article is protected by copyright. All rights reserved. 
Number of people with High a high fear of hypoglycaemia (\%)
Young people
Not availableA
$17 /$ of $33(52)$
$15 /$ of $22(6168)$
Parents
Not availableA
$31 /$ of 33 (94)
20/ of $22(91)$

*The $\mathrm{m}$ The median number of recorded $\mathrm{HbA}_{1 \mathrm{c}}$ values for each participant was 3 (range 1- -5). DCCT, Diabetes Control and Complications Trial; IQR, interquartile range; NA, not available.

Table 3 Quantitative evaluation.

\begin{tabular}{|c|c|c|}
\hline & $\begin{array}{c}\text { Child ( } \\
\text { Mean (Range) } N=21)\end{array}$ & $\begin{array}{c}\text { Parent } \\
\text { Mean (Range) } N=21)\end{array}$ \\
\hline \multicolumn{3}{|l|}{ Recommendation of the day } \\
\hline On the day* & $9.0(6.5--10)$ & $9.6(7.5--10)$ \\
\hline Follow up (22--109 days later) & $9.1(8--10)$ & $9.4(5--10)$ \\
\hline Usefulness of the day & $8.6(5--10)$ & $8.9(7--10)$ \\
\hline Enjoyment of the day & $8.9(3--10)$ & $9.1(5--10)$ \\
\hline \multicolumn{3}{|l|}{ Comfort speaking about diabetes } \\
\hline Before participation & $6.0(1--10)$ & $8.5(1--10)$ \\
\hline After participation & $7.4(3--10)$ & $8.8(1--10)$ \\
\hline
\end{tabular}

All values are given as median (range). $* N=22$ for evaluation on the day.

This article is protected by copyright. All rights reserved. 
Table 4 Baseline and follow follow-up data on the Hypoglycaemia Fear Survey (HFS) for YP young people and parents identified as having a high fear of hypoglycaemia at baseline. Higher scores indicate a higher greater fear of hypoglycaemia.

\begin{tabular}{|c|c|c|c|c|}
\hline & \multicolumn{2}{|c|}{ Young people } & \multicolumn{2}{|c|}{ Parents } \\
\hline & YP Baseline & $\begin{array}{c}\text { YP } \\
\text { Follow up }\end{array}$ & Parent Baseline & $\begin{array}{c}\text { Parent Follow } \\
\text { up }\end{array}$ \\
\hline & $(N=15)$ & $(N=9)$ & $(N==20)$ & $(N=17)$ \\
\hline & Mean (SD) & Mean (SD) & Mean (SD) & Mean (SD) \\
\hline $\begin{array}{l}\text { Behaviour score I } \\
\text { (maintenance of } \\
\text { high blood } \\
\text { glucose), mean } \\
\text { (SD) }\end{array}$ & $39.7(20.8)$ & $29.5(18.1)$ & $42.9(22.2)$ & $43.1(12.3)$ \\
\hline $\begin{array}{l}\text { Behaviour score } \\
\text { II (avoidance of } \\
\text { hypoglycaemic } \\
\text { risks), mean (SD) }\end{array}$ & $64.3(17.9)$ & $61.5(32.1)$ & $68.5(14.1)$ & $78.5(17.1)$ \\
\hline $\begin{array}{l}\text { Worry score, } \\
\text { mean (SD) }\end{array}$ & 39.7 (18.9) & $32.1(20.2)$ & $53.6(20.0)$ & $49.1(20.7)$ \\
\hline $\begin{array}{l}\text { Number with a } \\
\text { High high fear of } \\
\text { hypoglycaemia } \\
(\%)\end{array}$ & $15 /$ of $22(68)$ & $9 /$ of $18(50)$ & $20 /$ of $22(91)$ & $17 /$ of $19(89)$ \\
\hline
\end{tabular}

This article is protected by copyright. All rights reserved. 